\title{
TUMOR DESMÓIDE TRATADO COM TAMOXIFENO: RELATO DE CASO
}

\author{
BRUNO JUSTE WERNECK CÔRTES ${ }^{1}$, SINARA MÔNICA DE OLIVEIRA LEITE ${ }^{1}$, MARCOS HENRIQUE ROCHA \\ CAMPOS $^{1}$, LEVINDO ALVES DE OLIVEIRA ${ }^{l}$ \\ ${ }^{1}$ Hospital Governador Israel Pinheiro - IPSEMG - Belo Horizonte, Minas Gerais
}

CÔRTES BJW, LEITE SMO, CAMPOS MHR, OLIVEIRA LA. Tumor Desmóide Tratado com Tamoxifeno: Relato de Caso. Rev bras Coloproct, 2006;26(1):61-64.

RESUMO: O tumor desmóide (TD) é uma neoplasia benigna, que se origina de estruturas fasciais ou músculo-aponeuróticas, constituída por proliferação fibroblástica. Ocorre em 4 a $13 \%$ dos pacientes com polipose adenomatosa familiar (FAP). Apesar de histologicamente benignos, os TD têm comportamento maligno, sendo localmente invasivos e com elevada recorrência após ressecção. Os autores relatam um caso de tumor desmóide tratado cirurgicamente no Hospital Governador Israel Pinheiro - IPSEMG e fazem revisão da literatura sobre o tratamento.

Descritores: Tumores desmóides, tamoxifeno, polipose adenomatosa familiar

\section{INTRODUÇÃO}

O tumor desmóide (TD) é uma neoplasia benigna, que se origina de estruturas fasciais ou músculo-aponeuróticas, constituída por proliferação fibroblástica. É um tumor raro que representa $0,03 \%$ de todas as neoplasias. É diagnosticado, em sua maioria, entre os pacientes de 20 a 40 anos de vida, com variação de 5 meses aos 80 anos de idade. É mais prevalente em mulheres na idade reprodutiva. Ocorre em 4 a $13 \%$ dos pacientes com polipose adenomatosa familiar (FAP), sendo a segunda causa de morte nos pacientes com esta síndrome, perdendo apenas para o câncer de cólon. Os pacientes portadores de FAP têm $16 \%$ de risco cumulativo de desenvolver TD nos 10 anos após a realização da colectomia. Nos portadores de FAP, $50 \%$ dos TD são intra-abdominais, $40 \%$ localizam-se na parede abdominal e o restante nas extremidades. Apesar de histologicamente benignos, os TD têm comportamento maligno, sendo localmente invasivos e com elevada recorrência após ressecção. O objetivo deste trabalho é relatar um caso de tumor desmóide tratado cirurgicamente no Hospital Governador Israel Pinheiro - IPSEMG

\section{RELATO DO CASO}

GHPO, 56 anos, sexo feminino, viúva, natural e residente em Curvelo - MG, com história familiar de polipose adenomatosa familiar, foi submetida à colectomia total, com íleo-reto-anastomose, estando em controle ambulatorial para os pólipos retais. Após dois anos da cirurgia, desenvolveu quadro de dor e distensão abdominal difusa (Figura-1). A tomografia computado-

Trabalho realizado no Hospital Governador Israel Pinheiro - IPSEMG - Belo Horizonte, Minas Gerais.

$\overline{\text { Recebido em 09/05/2005 }}$

Aceito para publicação em 12/07/2005 
rizada abdominal demonstrou lesão compatível com tumor desmóide (Figura-2).

Submetida à laparotomia devido a semiobstrução intestinal foi evidenciada grande lesão sólida, envolvendo mesentério, intestino delgado e pâncreas (Figura-3 e 4). O tumor foi ressecado parcialmente com evidências de lesão residual no pâncreas (Figura-5). No pós-operatório evoluiu com íleo de resolução espontânea, recebendo alta hospitalar no 7o DPO. Tratada no pós-operatório com tamoxifeno, verificou-se desaparecimento da lesão residual observada durante acompanhamento tomográfico semestral. Encontra-se em avaliação ambulatorial há dois anos, sem evidência de progressão da doença como evidenciado em tomografia computadorizada de

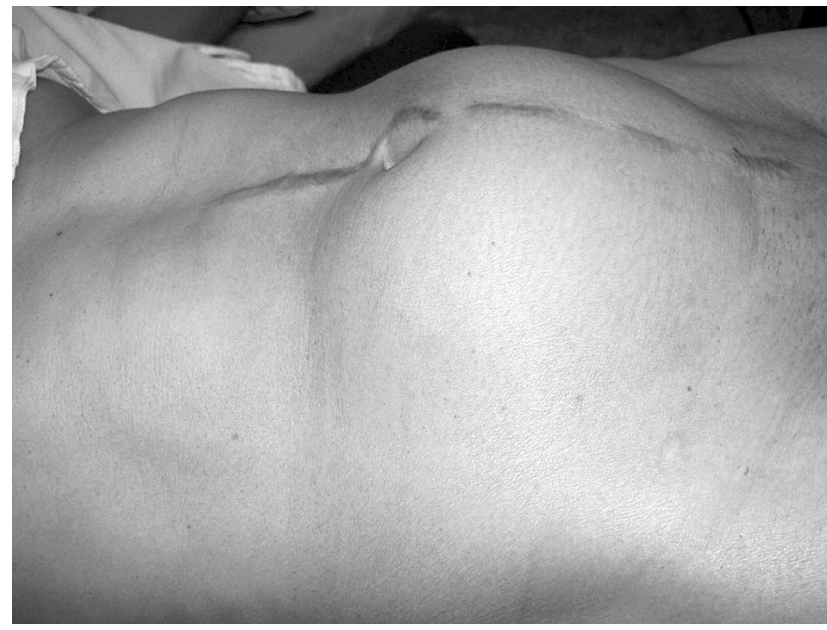

Figura 1

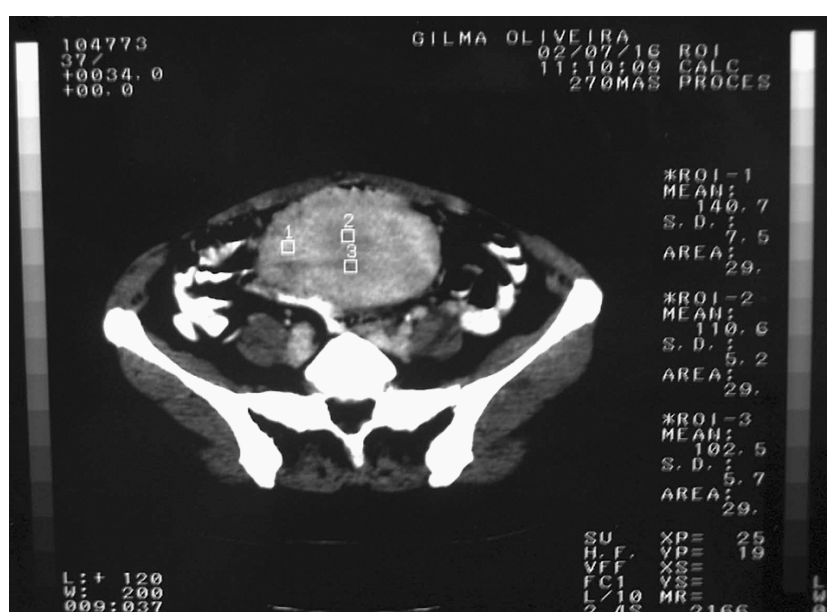

Figura 2

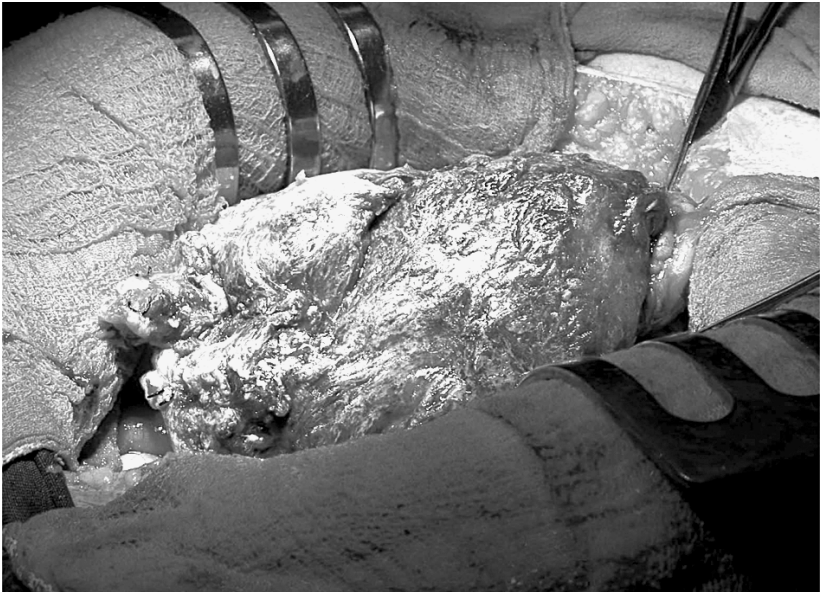

Figura 3

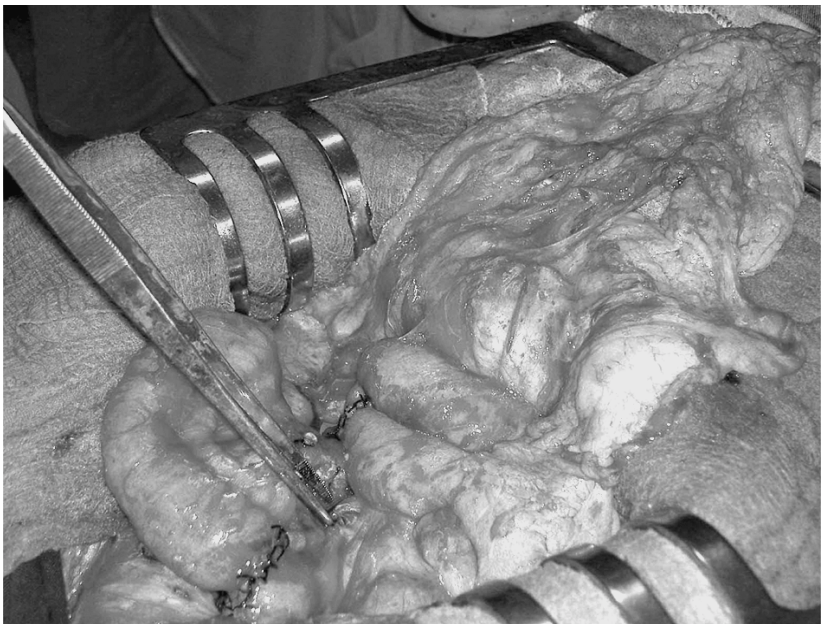

Figura 4

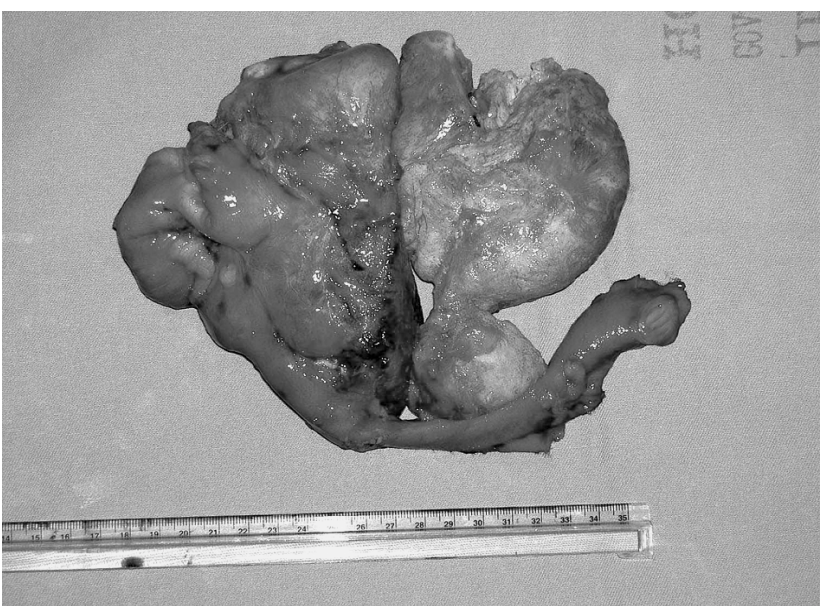

Figura 5 
controle e em uso de tamoxifeno. Tem hábito intestinal regular, embora evacue cerca de 5 vezes por dia, devido às ressecções intestinais já realizadas. Não apresenta déficit nutricional, trabalha como professora e tem boa qualidade de vida.

\section{DISCUSSÃO}

A etiologia dos TD não foi ainda totalmente esclarecida. Todavia, existem fatores reconhecidamente relacionados ao seu desenvolvimento: genéticos, traumáticos e hormonais. Os pacientes com TD, em sua maioria, são portadores de deleção dos alelos do gene APC (5q21-22) e mutações próximas ao códon 1444 deste gene. O trauma cirúrgico tem relação estabelecida com o aparecimento dos TD (68 a 83\% de chance); no entanto, a extensão ou o tipo de procedimento não interferem no risco desta incidência. Receptores estrogênicos parecem estar envolvidos na ocorrência dos tumores desmóides: pacientes grávidas ou em uso de anticoncepcionais orais apresentam crescimento dos TD, verificando-se sua regressão após a menopausa.

O tratamento dos TD é orientado pela sua localização, extensão a órgãos vitais ou se há presença de recidiva.

A introdução dos antiestrogênicos no tratamento monoterápico ou combinado dos tumores desmóides é baseado na resposta destes às variações hormonais. O tamoxifeno e o toremifene são as drogas de escolha nestes casos, pois 33 a $75 \%$ dos tumores desmóides apresentam receptores estrogênicos. A ação das drogas anti-estrogênicas é mediada através da inibição do TGF-beta nos fibroblastos. Entretanto, o efeito dos anti-estrogênicos não pode ser explicado apenas por suas ações nos receptores estrogênicos. Receptores específicos para drogas anti-estrogênicas foram encontrados em 79\% dos TD. Após o início da terapêutica, um efeito progressivo é verificado nas primeiras 2 semanas a 6 meses, com resposta positiva de $50 \%$ dos pacientes ao tratamento. As melhores evoluções foram encontradas com a associação das drogas anti-estrogênicas aos anti-inflamatórios não esteróides (Sulindac). Church ${ }^{6}$ sugere tratamento do tumor desmóide intra-abdominal na FAP com Sulindac, $150 \mathrm{mg}$ duas vezes ao dia. Se o tumor continua a crescer na observação clínica e tomográfica deve-se adicionar o tamoxifeno, $80 \mathrm{mg} / \mathrm{dia}$. Se o tumor estabiliza devese então continuar as medicações, mas reduzir a dose do tamoxifeno após 6 meses e ir retirando o medicamento progressivamente. Se o tumor continua a crescer ou se está sintomático, deve-se considerar a quimioterapia. Se um tumor desmóide é encontrado durante laparotomia e pode ser ressecado com um mínimo de intestino delgado e baixas complicações isto pode ser feito. Porém, se a excisão completa é impossível, melhor obter espécime para histologia e estudos para receptores estrogênicos.

A sobrevida geral dos pacientes portadores de TD em 10 anos é de $63 \%$ com 4 a $6 \%$ dos tumores regredindo espontaneamente. As principais causas de morte são: erosão de vaso sanguíneo ou sepse decorrente de fístula entérica, além de complicações secundárias ao tratamento cirúrgico.

SUMMARY: The desmoid tumors are benign tumors arising from fibroaponeurotic tissue. They occur in 4 to $13 \%$ patients who present familial adenomatous polyposis. Although a benign disease, desmoid tumors are focally invasive. They do not metastasize but can be lethal because of aggressive growth with pressure and erosion causing small bowel obstruction. Their tendency to recur $(65 \%$ to $85 \%)$ after removal has encouraged a conservative approach to management.

The authors report the case of a patient who presented intra-abdominal desmoid tumor, treated surgically in the Hospital Governador Israel Pinheiro - Belo Horizonte (MG) and discuss the therapeutic options in the literature.

Key words: desmoid tumors, tamoxifen, familial adenomatous polyposis

\section{REFERÊNCIAS BIBLIOGRÁFICAS}

1. Knudsen AL, Bulow S - Desmoid tumour in familial adenomatous polyposis. A review of literature. Familial Cancer; 1: 111-119, 2001
2. Bensom JR, Baum, M - Breast cancer, desmoid tumours and familial adenomatous poliposis - A unifying hypothesis. The Lancet; 342(Oct): 848-850, 1993.

3. Chao AS, Lai CH, Hsueh S, et al. - Successful treatment of 
recurrent pelvic desmoid tumour with tamoxifen. Human Reproduction; 15(2): 311-313, 2000.

4. Lewis JJ, Boland PJ, Leung DHY et al. - The enigma of desmoid tumors. Annals of Surgery; 229(6): 866-873, 1999.

5. Risum S, Bülow $\mathrm{S}$ - Doxorrubicin treatment of an intra-abdominal desmoid tumour in pacient with familial adenomatous polyposis. Colorrectal Disease; 5: 585-586, 2003.

6. Church JM. Desmoid tumors in patients with familial adenomatous polyposis. Semin Colon Rectal Surgery; 6:2932,1995 .

Endereço para correspondência: SINARA MÔNICA DE OLIVEIRA LEITE

Av. Contorno 4747 cj 912 - Serra

30.110-090 - Belo Horizonte (MG) 